\title{
PROPAGANDA NO FACEBOOK FUNCIONA? MENSURAÇÃO E ELABORAÇÃO DE UMA ESCALA DE ATITUDE ${ }^{1}$
}

\author{
Rafael Lucian ${ }^{2}$ \\ Jairo Dornelas ${ }^{3}$
}

http://dx.doi.org/10.1590/1413-2311.202.77577

\section{RESUMO}

Há muitas razões para que as empresas criem e mantenham seus perfis no facebook ${ }^{\circledR}$. Os sites sociais são grandes consumidores de tempo das pessoas na Internet e a mídia social vem atravessando o mais rápido crescimento na história da mídia. Desde que o facebook ${ }^{\circledR}$ tomou proporções globais, empresas de todos os segmentos apressadamente passaram a se dedicar à criação de seus perfis corporativos. Constata-se que o facebook ${ }^{\circledR}$ é gratuito para o usuário, logo a principal fonte de renda da rede são os anúncios publicitários. Neste sentido, o objetivo deste artigo foi mensurar a atitude de consumidores em relação à propaganda no facebook $^{\mathbb{R}}$ e para tal, construir e validar uma escala de mensuração de atitude dos usuários do facebook $^{\circledR}$ em relação à propaganda nesta plataforma. Concluiu-se através do sucesso da validação preditiva que a escala proposta possui a capacidade de mensurar a atitude dos usuários do facebook $^{\circledR}$ em relação à propaganda online e foi relevado, ainda, que os consumidores possuem atitude positiva em relação à propaganda nesta plataforma, ao passo que sentem um distanciamento entre as redes sociais e o ato da compra.

Palavra-chave: Mensuração de atitude. Mídias Sociais. Propaganda On-line. Protocolo de Elaboração de Escala. Atitude do Consumidor.

\footnotetext{
${ }^{1}$ Recebido em 21/10/2017, aprovado em 08/05/2018.

${ }^{2}$ Faculdade Boa Viagem (Recife, PE, Brasil) - rafael.lucian@,fbv.edu.br

${ }^{3}$ Universidade Federal de Pernambuco (Recife, PE, Brasil) - jairo@ufpe.br
} 


\title{
FACEBOOK 'S ADVERTISEMENT WORKS? MEASURING AND PROPOSING AN ATTITUDE SCALE
}

\begin{abstract}
There are many reasons that companies create and maintain profiles on facebook ${ }^{\circledR}$. The social sites are huge consumers of the time people spend on the internet and the social media is the fastest growing of all history in media. Since facebook ${ }^{\circledR}$ took on global proportions, companies in every sector rapidly created and published their corporate profiles. Since the use of facebook ${ }^{\circledR}$ is free of charge to users, the main source of the network's income is paid advertising. The objective of this article is to measure the consumer's attitude relative to ads on facebook ${ }^{\circledR}$ and to construct and validate a scale of measurement of attitude of the users of facebook $^{\circledR}$ relative to the advertising on this platform. It was concluded by successful predictive validation that the proposed scale can measure the attitude of the users of facebook $^{\circledR}$ in relation to online advertising and it was uncovered that users have positive attitude to ads even though they perceive a gap between this ads and purchase act.
\end{abstract}

Keywords: Measurement of attitude. Social Media. Online Advertising. Protocol Development Scale. Consumer Attitude.

\section{¿EL ANUNCIO DE FACEBOOK FUNCIONA? MEDICIÓN Y PROPONER UNA ESCALA DE ACTITUDES}

\section{RESUMEN}

Hay muchas razones por las que las empresas crean y mantienen perfiles en facebook ${ }^{\circledR}$. Los sitios sociales son grandes consumidores de las veces las personas pasan en Internet y los medios de comunicación social es el crecimiento más rápido de toda la historia en los medios de comunicación. Desde facebook ${ }^{\circledR}$ alcanzó proporciones globales, las empresas de todos los sectores crearon rápidamente y publicaron sus perfiles corporativos. Dado que el uso de facebook ${ }^{\circledR}$ es libre de costo para los usuarios, la principal fuente de ingresos de la red es la publicidad de pago. El objetivo de este trabajo es medir la actitud de los consumidores con respecto a los anuncios en facebook ${ }^{\circledR}$ y también para construir y validar una escala de medición de la actitud de los usuarios de Facebook ${ }^{\circledR}$ con respecto a la publicidad en esta 
plataforma. Se concluyó la validación predictiva de éxito que la escala propuesta tiene la capacidad de medir la actitud de los usuarios de Facebook ${ }^{\circledR}$ en relación con la publicidad en línea y fue descubierto que los usuarios tengan una actitud positiva a pesar de los anuncios que perciben una brecha entre estos anuncios y comprar acto.

Palabras clave: Medición de la actitud. Social Media. Publicidad online. Protocolo Escala de Desarrollo. Actitud del Consumidor.

\section{INTRODUÇÃO}

A sociedade humana pode ser investigada sob diversas perspectivas. Nas ciências sociais, há forte interesse em escrutinar assuntos relevantes às pessoas, incluindo as formas como essas se organizam, tomam decisões, lidam com tecnologia, constroem conhecimento e têm seu comportamento mensurado de modo empírico.

De fato, ao longo do tempo, o comportamento se caracterizou por interferir nas decisões e grande parte do interesse científico na área social concentrou-se em estudar esse comportamento. $\mathrm{Na}$ administração não foi diferente, pois comportamento é a base para o estudo das organizações. Constata-se, então, que as pessoas têm comportamento sócioorganizacional-grupal que cada vez mais se quer conhecido. Neste segmento particular, uma área consagrada, porém ainda promissora para estudos, refere-se a compreender como as pessoas reagem diante de situações conhecidas, ou seja, suas atitudes.

Atitude é uma pré-disposição, relativamente estável e organizada, para reagir na forma de opiniões (nível verbal) ou de atos (nível comportamental), em presença de objetos (pessoas, ideias, acontecimentos, coisas), de maneira determinada (KO et al., 2016), que representa uma posição mental consistente, manifesta, sobre algo ou alguém.

Sendo assim, é possível acessar a atitude de uma pessoa através da observação do seu comportamento ou se a própria pessoa a comunicar, pois atitude é essencialmente uma disposição mental em face de uma ação potencial (ZHANG et al., 2014; MARTIN, 2013). Se a observação dos atos é um procedimento que demanda mais tempo e praticamente inviabiliza estudos em grande escala, a mensuração das opiniões oferece diversas vantagens em relação à economia de recursos.

Ancoradas nesse perfil, as redes sociais, como o facebook $^{\circledR}$, são projetadas para mediar o relacionamento das pessoas e promover uma troca informacional mais fácil entre seus membros em base constante e permanente. Essas características enaltecem a 
possibilidade observacional do comportamento das pessoas através de suas opiniões declaradas, que são de fato manifestações de suas atitudes, pois acredita-se que nas redes sociais seja possível conhecer e entender como o homem lida, administra e é influenciado pelas tecnologias da informação.

Tais opiniões observadas na rede social facebook $^{\circledR}$ são das mais variadas intenções sendo que as duas formas mais comum são as relações entre usuário-usuário e usuárioempresas (AGGARWAL; VAIDYANATHAN; CASTLEBERRY, 2011). Para a investigação proposta neste artigo, a segunda forma recebe particular interesse, pois para o campo da administração de marketing é decisivo entender como o relacionamento entre consumidores e marcas está acontecendo nas plataformas digitais.

Entre as diversas formas de interação usuário-empresa, a mais tradicional é a interação publicitária, pois esta forma tradicional de comunicação desenvolvida amplamente em mídias off-line está sendo também utilizada em plataformas eletrônicas e a adaptação de formas e conteúdo de um modelo ao outro está demandando grande atenção por parte das empresas e da academia atualmente.

Considerando essa característica particular do facebook $^{\circledR}$ de registrar permanentemente a atitude de usuários em relação as comunicações publicitárias, surge o contexto para o desenvolvimento deste artigo que tem por objetivo criar uma escala de mensuração de atitude em relação a propaganda no facebook $^{\circledR}$ ao passo que investiga como este fenômeno está acontecendo.

Investigações nesta nova temática são desejadas tanto pelo mercado quanto pela academia, e a perspectiva da propaganda neste site se torna prioridade de pesquisa ao passo que é fonte de receita da empresa facebook ${ }^{\circledR}$ e uma nova mídia aparentemente promissora para anunciantes.

Os custos relativamente inferiores às mídias tradicionais de massa tornam as redes sociais ambientes propensos à comunicação publicitária, porém não há ainda consenso entre os estudiosos sobre a atitude dos usuários em relação aos anúncios neste ambiente. Considerando tal problemática, surge a pergunta de pesquisa: Qual a atitude de consumidores jovens em relação à propaganda no facebook ${ }^{\circledR}$ ?

Para atingir tal objetivo, será elaborado um instrumento de mensuração ad-hoc. A nova escala proposta pretende ser um instrumento validado e confiável tanto para a elaboração desta pesquisa quanto para que qualquer empresa ou pesquisador tenha possibilidade de mensurar a atitude de seu público alvo em relação à propaganda no 
facebook $^{\circledR}$. Conhecer essa atitude é fundamental para tomar decisões estratégicas de marketing, e com este objeto o próximo tópico apresenta o objeto base para mensuração.

\section{CONTEXTO DA PESQUISA}

O facebook $k^{\circledR}$ é uma rede social que foi lançada em 4 fevereiro de 2004, operada e de propriedade privada da Facebook Inc. Em outubro de 2017 o facebook ${ }^{\circledR}$ possuía 1,3 bilhões de usuários ativos por dia e 1,9 bilhões de usuários ativos em um mês, dos quais $85 \%$ são pessoas não residentes nos EUA (país sede) e 92\% acessam por plataformas móveis, como o celular (SOCIALBAKERS, 2017).

As redes sociais como o facebook ${ }^{\circledR}$ são plataformas que permitem a propagação da comunicação mediada por computador, nas quais as relações pessoais ganham um novo sentido que vai além do ato de comunicar e ser comunicado (ERMIŞ, 2016). Representam uma forma complexa de relacionamento entre indivíduos, grupos ou organizações agrupadas em torno de valores, crenças ou interesses comuns. O desenvolvimento ocorre a partir da interação e comunicação entre seus participantes, o que a configura como uma construção social (TIKNO, 2018).

Nesses locais virtuais, reúnem-se pessoas que podem compartilhar informações sobre elas mesmas ou qualquer assunto, bem como acessar perfis de outros usuários e manter conversas de forma direta ou indireta entre si (ERMIŞ, 2016). Nesse terreno, há uma grande preocupação com a construção de uma identidade cultural e com conceitos como os de aceitação e popularidade (KOC, 2016).

O Brasil é o $4^{\circ}$ país em número de usuários de internet em outubro de 2017 com 120 milhões de pessoas conectadas, perdendo apenas para Estados Unidos (242 milhões), Índia (333 milhões) e China (705 milhões) (EXAME, 2018).

A sucursal brasileira, por ser a segunda maior do mundo, possui muitos anunciantes que se relacionam com milhões de usuários diariamente. A Tabela 1 apresenta a listagem com as marcas que mais interagem (SOCIALBAKERS, 2017). As páginas com maiores seguidores brasileiros são a fanpage Cifras (40 milhões), seguido pela Coca-Cola (18 milhões) e Neymar Jr (16 milhões). Em números globais a página Neymar Jr é a fanpage brasileira de maior repercussão com 60 milhões de seguidores ao redor do planeta.

REAd | Porto Alegre - Vol. 23 - No 3 - Setembro / Dezembro 2017 - p. 189-217 
Tabela 1 - Marcas mais atuantes no facebook $^{\circledR}$ em 2017

\begin{tabular}{c|c|c}
\hline Site & Seguidores Brasileiros & Seguidores Total \\
\hline Cifras & 30 milhões & 40 milhões \\
\hline Coca-Cola & 18 milhões & 18 milhões \\
\hline Neymar Jr & 16 milhões & 60 milhões \\
\hline Luciano Huck & 16 milhões & 17 milhões \\
\hline Guaraná Antarctica & 15 milhões & 16 milhões \\
\hline Facebook & 15 milhões & 15 milhões \\
\hline Jorge e Mateus & 14 milhões & 15 milhões \\
\hline Aline Barros & 14 milhões & 15 milhões \\
\hline Esporte Interativo & 14 milhões & 14 milhões \\
\hline Multishow & 14 milhões & eñ
\end{tabular}

Fonte: página individual do Socialbakers, disponível em <www.socialbakers.com> Acesso em: 7 maio de 2018.

Embora o site de relacionamentos sociais não seja mais uma novidade, ainda atrai a atenção da academia. Yung (2017), por exemplo, acredita que a plataforma ainda é uma fonte adequada para as empresas direcionarem comunicação de marketing de segmento. Ermiş (2016), por sua vez, investigou a propaganda no facebook ${ }^{\circledR}$ e propôs uma nova estratégia de design para esta prática. Uma vez contextualizado o objeto de estudo, o próximo tópico apresenta o debate teórico que sustenta este estudo.

\section{REFERENCIAL TEÓRICO}

O universo das redes sociais mediadas por computador, embora seja algo relativamente recente já é bastante investigado e apreciado pela academia (DE VRIES, L; GENSLER, S; LEEFLANG, OS, 2017). Os estudos acompanharam o crescimento do número de usuários nessas plataformas e demonstram que o tema é de interesse dos pesquisadores, e entre as várias linhas de pesquisa possíveis neste contexto esse artigo se interessa especialmente pela atitude dos usuários em relação à propaganda na rede social facebook ${ }^{\circledR}$.

O referencial teórico divide-se em duas sessões, a problemática da atitude do consumidor ser positiva ou negativa em relação à propaganda na plataforma e o próprio esforço de mensuração deste fenômeno que sustenta os argumentos de ambos os lados. 


\subsection{ATITUDE NO $F A C E B O O K^{\circledR}$ EM RELAÇÃO À PROPAGANDA}

O embate teórico em relação à atitude dos consumidores à propaganda divide-se em duas correntes teóricas, os que acreditam que a propaganda desperta atitudes positivas e os contrários a essa posição.

Rauschnabel e Kammerlanderivens (2016) sabem que existem ataques constantes de consumidores contra as marcas. Diversas motivações explicam esse comportamento, o ponto central da investigação é que o ambiente online facilita esse comportamento. Os consumidores são mais rápidos e possuem mais facilidade de encontrar simpatizantes quando atacam as marcas em plataformas de redes sociais. Embora os ataques sejam inevitáveis, as propagandas são o alvo preferido dos “odiadores".

A força do ataque destes consumidores insatisfeitos é potencializada, então, pelas redes sociais e um ambiente de impacto negativo à marca é criado (SITORUS; IRWANSYAH, 2017). Evitar a exposição em redes sociais é uma forma das marcas se protegerem do ataque dos odiadores. A alternativa para as empresas não se exporem em plataformas de rede social é migrar investimentos para anúncios em sites de busca, que tem efetividade conhecida e evitam a interação desprotegida existente nas plataformas como o facebook $^{\circledR}$ (WU; LINLIN, 2011).

A despeito desta ameaça teórica de agressão às marcas, há ainda muitas razões para que as empresas criem e mantenham seus perfis no facebook ${ }^{\circledR}$. Os sites sociais são grandes consumidores de tempo das pessoas na Internet e a mídia social vem atravessando o mais rápido crescimento na história da mídia. Desde que o facebook ${ }^{\circledR}$ tomou proporções globais, empresas de todos os segmentos apressadamente passaram a se dedicar à criação de seus perfis corporativos, visando marcar presença também no meio digital, aproveitando-se do momento para fazer uso dessas ferramentas, a fim de disparar conteúdo publicitário. Como já exposto, o facebook $k^{\circledR}$ é gratuito para o usuário, logo a principal fonte de renda da rede são os anúncios publicitários.

A plataforma de rede social possui interesse em manter as empresas anunciando, por isso, a despeito do ataque dos consumidores às marcas, a propaganda é incentivada. Algumas empresas adotam medidas protetivas que por vezes minimizam a exposição das marcas aos odiadores, porém, não suspendem os anúncios (BLIZZARD, 2014).

A construção do debate passa obrigatoriamente pela definição e distinção entre publicidade e propaganda. A propaganda pode ser definida como um modo específico de apresentar informação pagas sobre um produto, marca, empresa ou política que visa 
influenciar a atitude de uma audiência para determinada causa, posição ou atuação. A publicidade por sua vez, é a comunicação não paga que pode acontecer de forma espontânea (NELSON, 1996; SMITH; LASSWELL, 2015). O objeto de estudo desta pesquisa é a propaganda, entretanto, a publicidade é consequência natural e está intrinsicamente ligada ao tema investigado.

O consumidor de hoje tem a possibilidade de conectar-se com as marcas de novas e de diversificadas maneiras (KUCHARSKA, 2017). Ainda para Kucharska (2017), a relação entre as empresas e as redes sociais está consolidada e é irreversível, pois mesmo quando a marca utiliza de locais próprios na rede como hotsites, as chamadas aos consumidores são sempre feitas através de redes sociais. Um destes canais, como os sites de comunidades, os quais promovem a discussão sobre as marcas para um público amplo e geral, de uma maneira que anteriormente não se via. Para o sucesso dessas marcas, é necessário estar em diálogo contínuo com seus compradores. O facebook $k^{\circledR}$ permite não só essa aproximação, mas também a indicação de tendências e necessidades desses consumidores. Essas necessidades surgem da massiva presença desse público nas mídias sociais.

O facebook $^{\circledR}$ estimula a participação do usuário e a interação com as empresas, tanto para o lado positivo (KUCHARSKA, 2017), quanto para o lado negativo (SITORUS; IRWANSYAH, 2017). Se um usuário curte algo, significa dizer que ele apoia determinada informação ou produto. Quando um indivíduo se dispõe a compartilhar um conteúdo publicitário, ele se coloca como testemunha do produto ou marca de forma espontânea, um fator relevante para os anunciantes. O usuário ainda pode se relacionar com a marca em tempo integral através das fanpages (HALIMAROS, 2014).

O debate sobre a positividade e negatividade da propaganda no facebook $^{\circledR}$ é dependente direto de outro debate fundamental, a mensuração desta atitude. Só através da observação empírica que os argumentos teóricos são confrontados para sua confirmação ou retratação. A próxima sessão aborda então a literatura de base para esta pesquisa.

\subsection{MENSURAÇÃO DA ATITUDE EM RELAÇÃO À PROPAGANDA NO FACEBOOK ${ }^{\circledR}$}

Esforços de mensuração de atitude na plataforma escolhida são realizados atualmente por diversos pesquisadores (ORR et al., 2009; DEBATIN et al., 2009; LEDBETTER et al., 2010; SMITH; LASSWELL, 2015; KUCHARSKA, 2017), porém pela natureza ampla do fenômeno atitude, os construtos findam por divergirem em relação ao objeto intencionado.

REAd | Porto Alegre - Vol. 23 - No 3 - Setembro / Dezembro 2017 - p. 189-217 
Grande parte dos estudos de atitude no facebook ${ }^{\circledR}$ preferem utilizar escalas já validadas ao invés de elaborar novos instrumentos, isto é, uma medida que economiza tempo e dependendo do construto investigado pode ser realizada sem prejuízos de mensuração. Uma exceção a este comportamento é o estudo de Andreassen et al. (2012) que se propôs a elaborar uma escala de mensuração sobre o vício dos usuários com esta plataforma. Outro estudo que investigou atitudes no facebook $^{\circledR}$ foi a proposição de Sabra (2017), este, por sua vez, abriu mão de adotar uma escala já existente e elaborou um estudo de duas etapas, onde os itens do instrumento surgem ao longo do processo. Outro caso de autores que propuseram instrumento próprio para tal objetivo foi Chen e Kimlin (2015).

Tanto Andreassen et al. (2012) quanto Chen e Kimlin (2015) e Sabra (2017) não fizeram referência a adoção de um protocolo em particular, o que afeta a validação do instrumento, sobretudo, para replicações do estudo. As escalas utilizadas para mensuração de atitude no contexto do facebook ${ }^{\circledR}$ são em grande maioria adaptações de instrumentos equivalentes de outros contextos, basicamente elaboradas originalmente para contextos de marketing off-line e que ao longo do tempo foram adaptadas e validadas ao ambiente virtual (EGEBARK; EKSTRÖM, 2011).

Existem alguns pontos comuns entre os trabalhos de Andreassen et al. (2012), Chen e Kimlin (2015), Sabra (2017) e Ellison et al. (2007) que é a adaptação de escalas de contextos diversos para mensuração de atitude no facebook $^{\circledR}$, embora seja uma prática popular autores como Rossiter (2002) a condenam sob a alegação de que alterações no contexto do fenômeno e na população estudada reduzem a capacidade de mensuração da escala.

Segundo Moseskim (2017) as escalas são instrumentos muito voláteis que quando não cercadas de cuidados metodológicos levam o pesquisador a uma visão nublada sobre o objeto de pesquisa. Sendo assim, a escala deve ser elaborada para um construto específico a fim de ter sua capacidade de mensuração otimizada, e complementarmente o autor afirma que o construto é formado pelo fenômeno mais seu contexto e público alvo (ROSSITER, 2002). Essa mesma perspectiva é compartilhada por Lucian e Dornelas (2015) que entendem que a construção de itens da escala é uma etapa fundamental da elaboração do instrumento e nela dever ser considerado todas as características contextuais do que será mensurado.

Sendo assim, a decisão de elaborar uma escala de mensuração de atitude em relação a propaganda no facebook ${ }^{\circledR}$ é sustentada pela necessidade de se criar um instrumento específico para o construto desejado objetivando a otimização da mensuração (LUCIAN; DORNELAS, 2015). A elaboração de um instrumento de mensuração é uma contribuição colateral desta pesquisa aos futuros interessados no tema.

REAd | Porto Alegre - Vol. 23 - No 3 - Setembro / Dezembro 2017 - p. 189-217 197 


\section{PROTOCOLO PARA ELABORAÇÃO DA ESCALA}

Ao se criar uma escala, tem-se a intenção de fazê-la de forma que sua aplicação seja a mais ampla possível, porém quanto mais restrito for seu foco melhor será sua capacidade de mensuração do objeto desejado. Ao se delimitar esse foco, defende-se que a principal diferença entre escalas seja o caráter formativo ou reflexivo da variável, e no caso da atitude ela é de ordem reflexiva (NAM; DONG; LEE, 2017; MOSESKIM, 2017).

Para o desenvolvimento deste estudo foi adotado o protocolo de elaboração de escalas de Lucian e Dornelas (2015), tal escolha se deve ao protocolo ter sido proposto especificadamente para o desenvolvimento de escalas de atitude tal qual o objetivo deste estudo. Justifica-se também a escolha pela atualização do protocolo que contempla novas possibilidades aqui julgadas como eficientes para a tarefa proposta que podem ser observadas na Figura 1.

Figura 1 - Protocolo de elaboração de escalas de Lucian e Dornelas (2015)

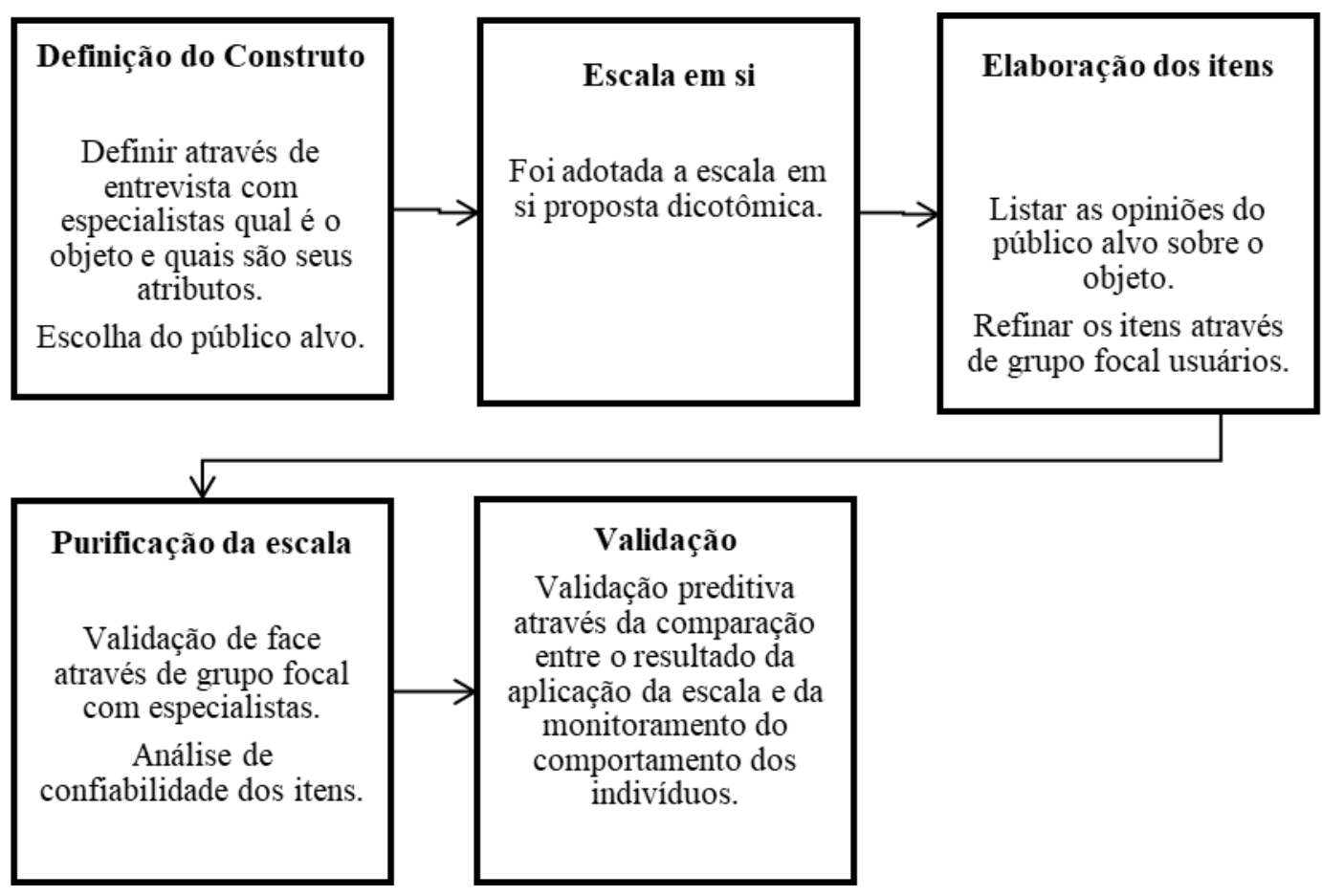

Fonte: Lucian e Dornelas (2015, p. 6).

Existem alguns protocolos disponíveis para a tarefa de elaboração de escalas de atitude, sendo assim é necessário justificar o motivo da escolha do protocolo em questão diante da gama de possibilidades. Os mais citados pela literatura são os protocolos de 
Churchill (1979) e Rossiter (2002). Sendo assim, o Quadro 1 apresenta um resumo dos passos destes protocolos antecedente à justificação da escolha.

Quadro 1 - Comparação entre os protocolos de elaboração de escalas

\begin{tabular}{|c|l|l|l|}
\hline Etapa $\backslash$ Autor & \multicolumn{1}{|c|}{ Churchill (1979) } & \multicolumn{1}{|c|}{ Rossiter (2002) } & \multicolumn{1}{|c|}{$\begin{array}{c}\text { Lucian e Dornelas } \\
\text { (2015) }\end{array}$} \\
\hline Definição do construto & Não abordado & Questões guias $\rightarrow$ & Questões guias \\
\hline Escala em si & Likert $\longrightarrow$ & Likert & Tipo Likert binária \\
\hline Elaborar itens & Não abordado & $\begin{array}{l}\text { Combinação entre } \\
\text { atributos o objetos }\end{array}$ & $\begin{array}{l}\text { Retirados de opiniões } \\
\text { claras e adequadas da } \\
\text { população }\end{array}$ \\
\hline Purificação da escala & Alfa de Cronbach $\longrightarrow$ & Alfa de Cronbach & TRI \\
\hline Validação da escala & $\begin{array}{l}\text { Análise fatorial } \\
\text { confirmatória }\end{array}$ & Preditiva $\longrightarrow$ & Preditiva MTMM \\
\hline
\end{tabular}

Fonte: elaborados pelos autores.

Os protocolos são mais citados pela literatura na ordem de sua antiguidade, logo o protocolo adotado é o mais recente e menos popular do trio, porém algumas características inovadoras foram destacadas para sua escolha que irão refletir na construção de uma escala diferenciada em relação aos trabalhos existentes.

O protocolo de Lucian e Dornelas (2015) inova no uso da técnica estatística de Teoria de Resposta ao Item (TRI) em substituição ao cálculo do coeficiente alfa para estimação da confiabilidade e na retomada da validação preditiva multimétodo (MTMM), que, embora quase centenária, estava completamente em desuso em administração, e foi renovada como alternativa viável e confiável para a validação de escalas reflexivas, como é o caso das escalas de mensuração de atitude. Além de incorporar novas técnicas ao desenvolvimento de escalas em administração, o protocolo escolhido também sugere uma escala em si inovadora.

O protocolo adotado segue uma sistemática tradicional que se inicia, então, com a definição do construto através de uma série de perguntas-guia que delimitam o objeto de estudo e já obriga o pesquisador a identificar as características e possibilidades de mensuração.

Enfatiza-se como razão da escolha a atualização da estatística utilizada no processo de purificação da escala, pois as ferramentas de TRI não eram populares ao tempo de Churchill (1979) e Rossiter (2002) e talvez por isso não foram incluídas em seus protocolos, visto o fato da performance dos testes de TRI serem superiores às estatísticas clássicas como o alfa de Cronbach (PASQUALI; PRIMI, 2003; SHU; SCHWARZ, 2014).

Outra condição decisiva para escolha do protocolo de Lucian e Dornelas (2015) é o fato deste ter sido projetado especificamente para elaboração de escalas de atitude. REAd | Porto Alegre - Vol. 23 - No 3 - Setembro / Dezembro 2017 - p. 189-217 199 
Evidenciado pela validação MTMM que é uma técnica própria de variáveis reflexivas e assim como a atitude podem ser observadas simultaneamente por duas manifestações correlacionadas como a opinião e o comportamento.

Naturalmente, observando o protocolo de Lucian e Dornelas (2015), é necessário propor o desenho da pesquisa. O objetivo deste desenho é apresentar esquematicamente os passos a serem cumpridos na elaboração da escala de mensuração de atitude dos usuários em relação à propaganda no facebook ${ }^{\circledR}$, sobretudo representar as coletas de dados que devem ser realizadas durante o processo.

Diante do exposto, os próximos subitens abordam pontualmente os passos seguidos pelo protocolo para elaboração da escala em questão.

\subsection{A DEFINIÇÃO DO CONSTRUTO}

O primeiro passo na elaboração de uma nova escala é a definição de construto e isto também foi observado pelo protocolo proposto. As perguntas-guia correspondem à proposição original do protocolo de Lucian e Dornelas (2015). Houve duas fontes para as respostas, julgamento pessoal dos pesquisadores e entrevista com especialistas, como permitido pelo protocolo adotado.

Foram realizadas entrevistas pessoais mediadas por computador através de e-mails com dez profissionais de propaganda que atuavam com o facebook $k^{\circledR}$. O número total de entrevistas se deu por critério de saturação. Foram inicialmente contatados cinco profissionais e em segunda rodada o mesmo número de pessoas foi alcançado.

Por julgamento pessoal os pesquisadores optaram por não realizar uma terceira rodada já que as respostas adicionais não acresceram novas informações. Sendo que o objetivo da entrevista era descobrir termos próprios do objeto em questão, a análise se deu por contagem de palavras.

Desta forma, o construto foi definido como a atitude dos usuários em relação à propaganda no site do facebook ${ }^{\circledR}$ que pode ser observada através dos comentários, link curtir, compartilhar, curtir fanpage ou número de pessoas indicado pelo valor do falando sobre isso e que seja fruto de interação entre o usuário e os links patrocinados, fanpages, publieditoriais e eventos (Quadro 2). 


\section{Quadro 2 - Definição do construto}

\begin{tabular}{|c|c|c|}
\hline Pergunta guia & Fonte da resposta & Resposta \\
\hline $\begin{array}{l}\text { Qual o construto que será } \\
\text { estudado? }\end{array}$ & $\begin{array}{l}\text { Julgamento pessoal dos } \\
\text { pesquisadores }\end{array}$ & $\begin{array}{l}\text { Atitude dos usuários } \\
\text { facebook }^{\circledR} \text { em relação } \\
\text { propaganda nesta rede }^{\text {à }}\end{array}$ \\
\hline $\begin{array}{l}\text { Quais são os limites deste } \\
\text { construto? }\end{array}$ & $\begin{array}{l}\text { Julgamento pessoal dos } \\
\text { pesquisadores }\end{array}$ & $\begin{array}{l}\text { Atitudes relacionadas aos } \\
\text { objetos publicitários no } \\
\text { facebook }^{\circledR} \text { excluindo-se a } \\
\text { atitude relacionada a qualquer } \\
\text { outro objeto }\end{array}$ \\
\hline $\begin{array}{l}\text { Quais são as manifestações } \\
\text { observáveis do construto? }\end{array}$ & $\begin{array}{l}\text { Entrevista com especialistas } \\
\text { através da questão: quais } \\
\text { são os indicadores de que } \\
\text { um anúncio publicitário } \\
\text { teve sucesso? }\end{array}$ & $\begin{array}{l}\text { Os comentários, links curtir, } \\
\text { compartilhar, curtir fanpage e o } \\
\text { número de pessoas indicado } \\
\text { pelo valor do falando sobre isso } \\
\text { no facebook }{ }^{\circledR}\end{array}$ \\
\hline $\begin{array}{l}\text { Quais são os objetos observáveis } \\
\text { do construto? }\end{array}$ & $\begin{array}{l}\text { Entrevista com especialistas } \\
\text { através da questão: quais os } \\
\text { tipos de anúncios } \\
\text { publicitários você acha que } \\
\text { existem no facebook }{ }^{\circledR} \text { ? }\end{array}$ & $\begin{array}{l}\text { As manifestações em relação } \\
\text { aos links patrocinados, } \\
\text { fanpages, publieditoriais } \\
\text { eventos no facebook }\end{array}$ \\
\hline $\begin{array}{l}\text { Quais são os atributos de cada } \\
\text { objeto observável do construto? }\end{array}$ & $\begin{array}{l}\text { Julgamento pessoal dos } \\
\text { pesquisadores }\end{array}$ & $\begin{array}{l}\text { Atributos não se aplicam à } \\
\text { atitude, os objetos observáveis } \\
\text { são a unidade mínima da atitude }\end{array}$ \\
\hline $\begin{array}{l}\text { Qual público se pretende ter como } \\
\text { respondente? }\end{array}$ & $\begin{array}{l}\text { Julgamento pessoal dos } \\
\text { pesquisadores }\end{array}$ & Usuários do facebook $k^{\circledR}$ \\
\hline
\end{tabular}

Fonte: elaborado pelos autores.

\subsection{A DEFINIÇÃO DA ESCALA EM SI}

Existem algumas opções de escala em si disponíveis, porém com objetivo de não descaracterizar o protocolo de Lucian e Dornelas (2015) adotado, optou-se por utilizar a escala em si própria do protocolo em questão, tal fato é importante por manter o alinhamento entre a coleta de dados e as análises propostas para a validade da escala em desenvolvimento.

Existem três diferenças entre a escala Lucian e Dornelas (2015) e a dominante de Likert (1932) que são o fato de não se utilizar números como rótulos para os pontos, o deslocamento do ponto neutro para fora da escala e a dicotomização da variável atitude. É importante enfatizar que as escalas dicotômicas são aceitas pela literatura e podem ser utilizadas sem prejuízo à confiabilidade ou efetividade da mensuração (KOMORITA, 1961; JACOB; MATELL, 1971; LUCIAN; DORNELAS, 2015).

Na sequência é realizada a etapa de elaboração dos itens da escala, e é onde se inicia propriamente a redação da escala. Essa fase envolve coleta de dados primários e suas particularidades são apresentadas no próximo tópico. 


\subsection{A ELABORAÇÃO DOS ITENS DA ESCALA}

A elaboração dos itens, terceiro passo do protocolo, teve início a partir da coleta de opiniões de usuários da rede social em questão através de amostragem do tipo bola de neve. Inicialmente, coletaram-se 195 respostas para a pergunta: qual a sua opinião sobre a propaganda no facebook $^{\circledR}$. Após coletado, o conjunto inicial de itens sofreu a primeira intervenção externa.

Um grupo de especialistas, publicitários com atuação em mídias sociais, foi convidado para inicialmente separar as opiniões entre positivas e negativas, claras e não claras, adequadas e inadequadas ao propósito da mensuração mediante grupo focal. As alternativas que não foram consideradas claras e as inadequadas foram eliminadas. Em seguida, se reduziu cada grupo restante (positivas e negativas) a um número adequado de itens para formar o questionário final. A versão preliminar resultou na seleção de 20 itens (Quadro 3).

\section{Quadro 3 - Elaboração dos itens da escala proposta}

\begin{tabular}{|l|c|c|c|c|c|}
\hline \multicolumn{1}{|c|}{ Item } & Sentido & Fanpage & $\begin{array}{c}\text { Links } \\
\text { patrocinad } \\
\text { os }\end{array}$ & Eventos & $\begin{array}{c}\text { Publieditori } \\
\text { ais }\end{array}$ \\
\hline $\begin{array}{l}\text { A quantidade de propaganda é } \\
\text { exagerada. }\end{array}$ & - & $\mathrm{S}$ & $\mathrm{S}$ & $\mathrm{S}$ & $\mathrm{S}$ \\
\hline Acho a propaganda prática e rápida & + & $\mathrm{S}$ & $\mathrm{S}$ & $\mathrm{S}$ & $\mathrm{S}$ \\
\hline $\begin{array}{l}\text { Acho bom, pois é uma ferramenta } \\
\text { rápida de busca }\end{array}$ & + & $\mathrm{S}$ & $\mathrm{S}$ & $\mathrm{S}$ & $\mathrm{N}$ \\
\hline Acho desagradável & - & $\mathrm{S}$ & $\mathrm{S}$ & $\mathrm{S}$ & $\mathrm{S}$ \\
\hline $\begin{array}{l}\text { Acho que as propagandas no } \\
\text { facebook } k^{\circledR} \text { são ótimas }\end{array}$ & + & $\mathrm{S}$ & $\mathrm{S}$ & $\mathrm{S}$ & $\mathrm{S}$ \\
\hline $\begin{array}{l}\text { Acho que é um acesso fácil à } \\
\text { informação }\end{array}$ & + & $\mathrm{S}$ & $\mathrm{S}$ & $\mathrm{S}$ & $\mathrm{S}$ \\
\hline $\begin{array}{l}\text { Acho válida a presença da } \\
\text { propaganda no facebook }\end{array}$ & + & $\mathrm{S}$ & $\mathrm{S}$ & $\mathrm{S}$ & $\mathrm{S}$ \\
\hline Ajuda-me na aquisição de produtos & + & $\mathrm{S}$ & $\mathrm{S}$ & $\mathrm{S}$ & $\mathrm{S}$ \\
\hline $\begin{array}{l}\text { As promoções de compartilhamento } \\
\text { são falsas, ninguém ganha }\end{array}$ & - & $\mathrm{S}$ & $\mathrm{N}$ & $\mathrm{N}$ & $\mathrm{S}$ \\
\hline Eu acho bastante útil & + & $\mathrm{S}$ & $\mathrm{S}$ & $\mathrm{S}$ & $\mathrm{S}$ \\
\hline Eu nunca acesso esses conteúdos & - & $\mathrm{S}$ & $\mathrm{S}$ & $\mathrm{S}$ & $\mathrm{S}$ \\
\hline $\begin{array}{l}\text { Gosto das fanpages, pois são } \\
\text { assuntos do meu interesse }\end{array}$ & + & $\mathrm{S}$ & $\mathrm{N}$ & $\mathrm{N}$ & $\mathrm{N}$ \\
\hline Gosto de promoções no facebook $k^{\circledR}$ & + & $\mathrm{S}$ & $\mathrm{S}$ & $\mathrm{N}$ & $\mathrm{N}$ \\
\hline $\begin{array}{l}\text { Interessante, pois traz novos } \\
\text { conteúdos }\end{array}$ & + & $\mathrm{S}$ & $\mathrm{S}$ & $\mathrm{N}$ & $\mathrm{S}$ \\
\hline $\begin{array}{l}\text { Mantém-me atualizado (a) sobre as } \\
\text { marcas }\end{array}$ & + & $\mathrm{S}$ & $\mathrm{S}$ & $\mathrm{N}$ & $\mathrm{S}$ \\
\hline Não curto a propaganda no & - & $\mathrm{S}$ & $\mathrm{S}$ & $\mathrm{S}$ & $\mathrm{S}$ \\
\hline
\end{tabular}

REAd | Porto Alegre - Vol. 23 - No 3 - Setembro / Dezembro 2017 - p. 189-217 


\begin{tabular}{|l|c|c|c|c|c|}
\hline facebook $^{\circledR}$ & & & & \\
\hline $\begin{array}{l}\text { O facebook } k^{\circledR} \text { tem mais propaganda } \\
\text { que as outras redes sociais, às vezes } \\
\text { enchem }\end{array}$ & - & $\mathrm{S}$ & $\mathrm{S}$ & $\mathrm{S}$ & $\mathrm{S}$ \\
\hline $\begin{array}{l}\text { O que incomoda é o fato da } \\
\text { propaganda ser invasiva }\end{array}$ & - & $\mathrm{N}$ & $\mathrm{N}$ & $\mathrm{S}$ & $\mathrm{S}$ \\
\hline $\begin{array}{l}\text { Os convites para eventos me } \\
\text { incomodam }\end{array}$ & - & $\mathrm{N}$ & $\mathrm{N}$ & $\mathrm{S}$ & $\mathrm{N}$ \\
\hline $\begin{array}{l}\text { Propaganda compartilhada por } \\
\text { amigos no facebook } k^{\circledR} \text { é confiável }\end{array}$ & + & $\mathrm{N}$ & $\mathrm{N}$ & $\mathrm{N}$ & $\mathrm{S}$ \\
\hline $\begin{array}{l}\text { Ultrapassa o limite de publicações e } \\
\text { afeta as notificações }\end{array}$ & - & $\mathrm{S}$ & $\mathrm{N}$ & $\mathrm{S}$ & $\mathrm{S}$ \\
\hline
\end{tabular}

Fonte: elaborado pelos autores.

Os itens deveriam abordam as quatro peças publicitárias que compõem o objeto observável da variável latente e que foram identificadas na fase de identificação do construto. Os itens, além de identificáveis pelas suas relações com o objeto, revelam possibilidades de classificação em positivos ou negativos, pois esta é uma forma prática de se observar algum padrão de resposta não desejável, como por exemplo, assinalar concordância para todas as positivas e também as negativas.

Uma vez que os itens foram identificados, a próxima etapa é purificar a escala, esse processo antecede a validação e tem o objetivo de preparar a escala para tal, os procedimentos podem ser observados no próximo tópico.

\subsection{A PURIFICAÇÃO DA ESCALA}

Após a definição da versão preliminar da escala, nos moldes relatados até então, os pesquisadores promoveram uma validação de face. Esta validação teve o objetivo de observar a concordância do grupo de especialistas convidados com a capacidade de a escala mensurar o construto pretendido.

Quinze especialistas foram convidados a julgar individualmente se cada item era adequado ( $\operatorname{sim}$ ou não) e claro ( $\operatorname{sim}$ ou não) aos propósitos de mensuração do construto desenvolvido para o teste do protocolo.

O grupo de especialistas é formado por pessoas graduadas em publicidade e propaganda que atuam em agências de propaganda com trabalhos em mídias sociais. $\mathrm{O}$ recrutamento do grupo foi feito através de e-mail aos alunos egressos de uma instituição de ensino superior, dos quais quinze se acusaram como pertencentes ao grupo de perfil desejado e concordaram em comparecer ao grupo focal. O perfil do grupo é de idade média de 25 anos, 
com experiência profissional na área de mídias sociais de pelo menos um ano e se divide entre 9 mulheres e 6 homens.

A escolha por ser realizar o grupo focal é em consonância com o protocolo de elaboração de escalas adotado, e tal técnica é respaldada para coleta de dados adicionais em pesquisas desta natureza por diversos autores (MORGAN, 1997; TAUSCH; MENOLD, 2016; KRUEGER; CASEY, 2000). Neste caso, por preceder a análise de dados, o objetivo do uso de grupos focais é auxiliar o pesquisador a obter um conhecimento prévio de seu universo de pesquisa, permitindo que ele se familiarize com o vocabulário e as ideias de seu público-alvo a fim de fazer inferências bem focadas sobre a população a ser pesquisada, em seguida, através de estudos quantitativos (LINDEGAARD, 2014).

Os valores percentuais da Tabela 2 representam a aprovação dos itens na validação de conteúdo. Foi adotado o valor arbitrário de 60\% como percentual mínimo de aceitação de acordo com a proposta original de Lucian e Dornelas (2015). Os itens com baixo desempenho na validação de face foram excluídos, pois não foram julgados adequados, ou seja, não foram capazes de contribuir para a mensuração em questão, qual seja mensurar atitude.

\section{Tabela 2 - Validação de face dos itens da escala proposta}

\begin{tabular}{l|c|c}
\multicolumn{1}{c|}{ Item } & Adequação & Clareza \\
\hline A quantidade de propaganda é exagerada & $67 \%$ & $80 \%$ \\
\hline Acho a propaganda prática e rápida & $73 \%$ & $73 \%$ \\
\hline Acho bom, pois é uma ferramenta rápida de busca & $47 \%$ & $60 \%$ \\
\hline Acho desagradável & $40 \%$ & $67 \%$ \\
\hline Acho interessante, pois traz novos conteúdos & $80 \%$ & $67 \%$ \\
\hline Acho que as propagandas no facebook ${ }^{\circledR}$ são ótimas & $87 \%$ & $87 \%$ \\
\hline Acho que é um acesso fácil à informação & $60 \%$ & $67 \%$ \\
\hline Acho válida a presença da propaganda no facebook ${ }^{\circledR}$ & $93 \%$ & $93 \%$ \\
\hline Ajuda-me na aquisição de produtos & $73 \%$ & $93 \%$ \\
\hline As promoções de compartilhamento são falsas, ninguém ganha & $33 \%$ & $73 \%$ \\
\hline Eu acho bastante útil & $80 \%$ & $87 \%$ \\
\hline Eu nunca acesso a esses conteúdos & $53 \%$ & $73 \%$ \\
\hline Gosto das fanpages, pois são assuntos do meu interesse & $80 \%$ & $93 \%$ \\
\hline Gosto de promoções no facebook & $80 \%$ & $93 \%$ \\
\hline Mantém-me atualizado (a) sobre as marcas & $93 \%$ & $87 \%$ \\
\hline Não curto a propaganda no facebook ${ }^{\circledR}$ & $47 \%$ & $73 \%$ \\
\hline O facebook ${ }^{\circledR}$ tem mais propaganda que as outras redes sociais, às vezes & $60 \%$ & $60 \%$ \\
enchem & & \\
\hline O que incomoda é o fato da propaganda ser invasiva & $60 \%$ & $73 \%$ \\
\hline Os convites para eventos me incomodam & $87 \%$ & $93 \%$ \\
\hline Propaganda compartilhada por amigos no facebook ${ }^{\circledR}$ é confiável & $53 \%$ & $80 \%$ \\
\hline Ultrapassa o limite de publicações e afeta as notificações & $27 \%$ & $60 \%$ \\
\hline
\end{tabular}

Fonte: elaborados pelos autores.

REAd | Porto Alegre - Vol. 23 - No 3 - Setembro / Dezembro 2017 - p. 189-217 
A sugestão de corte dos itens foi embasada na realização do grupo focal com especialistas. A partir da opinião deles e de seus votos em favor da adequação e clareza dos itens é que foi tomada a decisão de manter ou retirar algum item da escala. A seleção dos itens restantes que foram utilizados na próxima etapa é apresentada no Quadro 5.

\section{Quadro 5- Itens da escala proposta}

\begin{tabular}{|c|l|}
\hline Item & \multicolumn{1}{c|}{ Afirmação } \\
\hline A1 & Acho que as propagandas no acebook $^{\circledR}$ são ótimas. \\
\hline A2 & Acho que é um acesso fácil à informação. \\
\hline A3 & A quantidade de propaganda é exagerada. \\
\hline A4 & Mantém-me atualizado (a) sobre as marcas. \\
\hline A5 & Acho a propaganda prática e rápida. \\
\hline A6 & Eu acho bastante útil. \\
\hline A7 & Gosto de promoções no facebook $\AA$. \\
\hline A8 & Gosto das fanpages, pois são assuntos do meu interesse. \\
\hline A9 & Os convites para eventos me incomodam. \\
\hline A10 & Ajuda-me na aquisição de produtos. \\
\hline A11 & Acho válida a presença da propaganda no facebook $^{\circledR}$. \\
\hline A12 & $\begin{array}{l}\text { O facebook } \text { fan tem mais propaganda que as outras redes sociais, às vezes enchem a } \\
\text { paciência. }\end{array}$ \\
\hline A13 & Acho interessante, pois a propaganda traz novos conteúdos. \\
\hline A14 & O que incomoda é o fato de a propaganda ser invasiva. \\
\hline
\end{tabular}

Fonte: elaborados pelos autores.

Dando continuidade ao processo de purificação da escala, foi necessário estimar a confiabilidade. Para esta etapa, a técnica escolhida foi a TRI de três parâmetros, como sugerido pelo protocolo original de Lucian e Dornelas (2015). Desta forma, a escala foi aplicada em forma de censo com todos os alunos de uma IEE privada que possuíam conta ativa no facebook $^{\circledR}$. Acredita-se que para estimação da confiabilidade esse público fora adequado, pois a TRI não possui qualquer exigência de amostragem para sua realização e atende ao número de no mínimo 500 questionários válidos, necessário à calibração da TRI.

Obtiveram-se 845 questionários válidos que foram tabulados e analisados pelo programa IRTPRO ${ }^{\circledR}$ 2.1.2 para análises de teoria de resposta ao item. Observou-se que alguns itens não estavam na faixa de confiabilidade indicada pelo protocolo de Lucian e Dornelas (2015) que é entre 0,85 e 1,70; sendo assim optou-se por excluir o item com menor valor de $a$ e realizar um reteste até que todos se apresentem dentro da faixa ideal, esse procedimento foi realizado cinco vezes (Tabela 3 ). 
Tabela 3 - Cálculo da confiabilidade dos itens da escala proposta

\begin{tabular}{c|l|c}
\hline Item & \multicolumn{1}{|c|}{ Afirmação } & $\boldsymbol{1}$ \\
\hline A1 & Acho que as propagandas no facebook $k^{\circledR}$ são ótimas & 0,76 \\
\hline A2 & Acho que é um acesso fácil à informação & 0,01 \\
\hline A3 & A quantidade de propaganda é exagerada & 0,73 \\
\hline A4 & Mantém-me atualizado (a) sobre as marcas & 0,64 \\
\hline A5 & Acho a propaganda prática e rápida & 0,35 \\
\hline A6 & Eu acho bastante útil & 0,00 \\
\hline A7 & Gosto de promoções no facebook ${ }^{\circledR}$ & 0,95 \\
\hline A8 & Gosto das fanpages, pois são assuntos do meu interesse & 0,88 \\
\hline A9 & Os convites para eventos me incomodam & 1,04 \\
\hline A10 & Ajuda-me na aquisição de produtos & 0,56 \\
\hline A11 & Acho válida a presença da propaganda no facebook $k^{\circledR}$ & 0,00 \\
\hline A12 & $\begin{array}{l}\text { O facebook } \text { fem }^{\circledR} \text { mais propaganda que as outras redes sociais, às vezes enchem a } \\
\text { paciência }\end{array}$ & 1,04 \\
\hline A13 & Acho interessante, pois a propaganda traz novos conteúdos & 0,02 \\
\hline A14 & O que incomoda é o fato de a propaganda ser invasiva & 1,11 \\
\hline
\end{tabular}

Fonte: elaborados pelos autores.

A Tabela 4 apresenta o reteste da TRI apenas com os nove itens restantes. Essa verificação é necessária para que se observe o comportamento da escala com um número reduzido de itens.

\section{Tabela 4 - Reteste de confiabilidade dos itens da escala proposta}

\begin{tabular}{|c|c|c|}
\hline Item & Afirmação & $a$ \\
\hline A1 & Acho que as propagandas no facebook® são ótimas. & 1,31 \\
\hline A3 & A quantidade de propaganda é exagerada. & 1,31 \\
\hline A4 & Mantém-me atualizado (a) sobre as marcas. & 1,11 \\
\hline A7 & Gosto de promoções no facebook $\mathbb{R}$. & 1,58 \\
\hline A8 & Gosto das fanpages, pois são assuntos do meu interesse. & 1,62 \\
\hline A9 & Os convites para eventos me incomodam. & 1,43 \\
\hline A10 & Ajuda-me na aquisição de produtos. & 0,91 \\
\hline A12 & $\begin{array}{l}\mathrm{O} \text { facebook }{ }^{\circledR} \text { tem mais propaganda que as outras redes sociais, às vezes enchem a } \\
\text { paciência. }\end{array}$ & 1,68 \\
\hline A14 & O que incomoda é o fato de a propaganda ser invasiva. & 1,63 \\
\hline
\end{tabular}

Fonte: elaborados pelos autores.

A flutuação dos valores de $a$ ao se modificar o total de itens de uma escala é esperada. Porém esta variação deve permanecer os valores dentro da faixa de confiabilidade e foi este o comportamento observado dos itens analisados.

A variabilidade dos valores de $a$ corresponde à contribuição de informação do item em relação aos demais itens do teste. Embora na TRI o escore dos itens seja independente da variação dos casos, não o é da relação com os demais itens. Essa alteração em questão do

REAd | Porto Alegre - Vol. 23 - No 3 - Setembro / Dezembro 2017 - p. 189-217 
valor do parâmetro $a$ após manipulação dos itens da escala é conhecida e por isso recomendase o reteste de confiabilidade, pois, em alguns casos os resultados podem sugerir exclusão de novos itens. Se os novos valores de $a$ estiverem dentro do intervalo recomendado, a escala é dita confiável e pode seguir finalmente para a validação, tema do próximo tópico.

\subsection{VALIDAÇÃO DA ESCALA}

Em alinhamento com o protocolo de Lucian e Dornelas (2015), a validação proposta teve dois métodos de coleta de dados (por opinião e pelo comportamento), os quais mensuraram o mesmo construto (atitude).

Enquanto o método principal deve ser obrigatoriamente o levantamento fazendo uso de questionário onde é contida a escala em teste, o método alternativo escolhido foi o monitoramento de site em oito contas de facebook ${ }^{\circledR}$. Essas contas pertencem a oito voluntários que se dispuseram a colaborar com esta pesquisa, este grupo é composto por bolsistas de iniciação científica que cursavam há época o último ano da graduação do curso de publicidade e propaganda com idade média de 21 anos. Em média, as contas possuem 571 amigos, os quais têm idade média de 28 anos e que em sua maioria acessa ao facebook $^{\circledR}$ várias vezes por dia (74\%), de casa (54\%), do trabalho (43\%) e do celular (65\%), ou seja, respondentes que indubitavelmente têm a qualificação necessária para participarem desta pesquisa.

A Tabela 5 apresenta o resultado do monitoramento que foi feito da interação das pessoas com as propagandas no facebook ${ }^{\circledR}$. O ranking tomou por critério o ordenamento da maior para a menor porcentagem de interação no item curtir. Pode-se observar que esta ordem se mantém para a variável compartilhar, que é uma atitude positiva, demonstrando que há uma coincidência de resultados em todos os grupos.

Tabela 5 - Monitoramento das variáveis no facebook $^{\circledR}$

\begin{tabular}{c|c|c|c|c|c}
\hline Grupo & $\begin{array}{c}\text { Total de } \\
\text { amigos }\end{array}$ & $\begin{array}{c}\text { Total de } \\
\text { propagandas no } \\
\text { período }\end{array}$ & $\begin{array}{c}\text { Média de } \\
\text { 'curtir' }\end{array}$ & $\begin{array}{c}\text { Média de } \\
\text { 'compartilhar' }\end{array}$ & $\begin{array}{c}\text { Ranking } \\
\text { Atitude } \\
\text { Positiva }\end{array}$ \\
\hline G4 & 491 & 31 & $65 \%$ & $13 \%$ & $1^{\text {o }}$ \\
\hline G5 & 307 & 25 & $26 \%$ & $6 \%$ & $2^{\text {o }}$ \\
\hline G2 & 568 & 15 & $24 \%$ & $4 \%$ & $3^{\text {o }}$ \\
\hline G3 & 775 & 12 & $13 \%$ & $3 \%$ & $4^{\text {o }}$ \\
\hline G1 & 790 & 14 & $4 \%$ & $1 \%$ & $5^{\text {o }}$ \\
\hline G8 & 169 & 25 & $1 \%$ & $1 \%$ & $6^{\text {o }}$ \\
\hline G7 & 973 & 18 & $1 \%$ & $0 \%$ & $7^{\text {o }}$ \\
\hline
\end{tabular}

Fonte: elaborados pelos autores.

REAd | Porto Alegre - Vol. 23 - No 3 - Setembro / Dezembro 2017 - p. 189-217 207 
Cada peça publicitária que surgiu no feed de notícias do usuário foi analisada objetivamente através da contagem de frequência dos cliques em curtir e compartilhar. $\mathrm{O}$ objetivo deste monitoramento foi criar uma hierarquia entre os grupos e descobrir qual destes possuía atitude mais positiva em relação à propaganda. Este resultado é importante para servir de base de comparação na validação preditiva. O cálculo da interação foi a média de cliques em curtir e compartilhar. Como forma de normalizar os dados, cada frequência de cliques foi dividida pelo total de amigos do grupo.

Os grupos amostrais foram delimitados pelo próprio escopo do facebook ${ }^{\circledR}$, ou seja, cada grupo é formado pela rede de relacionamento de cada um dos oito voluntários da pesquisa, e por isto tende a apresentar como característica a homogeneidade. Enfatiza-se que para o objetivo desta pesquisa não há problemas em relação ao possível viés que isto implique ao trabalho. A mensuração da atitude não é prejudicada caso todos os sujeitos apresentem a mesma atitude, em verdade esse viés poderá inclusive ser útil para a validação da escala, pois se a resposta extrema for capitada por ambos os métodos será uma evidência de que o instrumento é capaz de mensurar o construto.

Ao final do período de monitoramento, foram aplicados questionários online através da plataforma GoogleDocs ${ }^{\circledR}$ com os oito grupos que foram observados. Isto gerou um banco de dados com 839 casos como discriminado na Tabela 6.

Observa-se que nenhum grupo atingiu o número de questionários desejados e isso se justifica pela resistência de grande parte da amostra em responder ao questionário. Durante os 23 dias de coleta de dados, tentou-se obter o maior número possível de respondentes, porém parte da amostra simplesmente não respondeu à solicitação.

Tabela 6 - Total de respondentes da coleta de dados por levantamento

Fonte: elaborados pelos autores.

\begin{tabular}{c|c|c}
\hline Grupo & Meta & Obtidos \\
\hline G1 & 266 & 113 \\
\hline G2 & 235 & 104 \\
\hline G3 & 264 & 65 \\
\hline G4 & 220 & 119 \\
\hline G5 & 174 & 173 \\
\hline G6 & 221 & 89 \\
\hline G7 & 283 & 101 \\
\hline G8 & 119 & 75 \\
\hline
\end{tabular}

REAd | Porto Alegre - Vol. 23 - No 3 - Setembro / Dezembro 2017 - p. 189-217 208 
Lamenta-se o fato do insucesso quanto às metas amostrais, porém sabe-se que para o efeito desejado de validação da escala, as regras de pré-teste assumem como válida a amostragem não probabilística intencional (ETIKAN, 2017), que possui menos rigor do que a amostragem realizada nesta tese. Enfatiza-se, também, que os testes descritivos que foram realizados aqui não dependem de parametrização, sendo, então, aceitável o resultado da coleta de dados.

$\mathrm{Na}$ sequência, os itens foram analisados com auxílio do software SPSS $^{\circledR} 20.0$ e estabelecidos os valores dos escores obtidos para o construto atitude. Estes escores estão listados e apresentados na Tabela 7 juntamente com a posição final de cada um no ranking de atitude positiva em relação à propaganda no facebook ${ }^{\circledR}$.

Tabela 7 - Análise do levantamento

Fonte: elaborados pelos autores.

\begin{tabular}{c|c|c}
\hline Grupo & Escore & Posição no ranking \\
\hline G4 & 4,85 & $1^{\circ}$ \\
\hline G5 & 3,51 & $2^{\circ}$ \\
\hline G2 & 3,04 & $3^{\circ}$ \\
\hline G1 & 1,73 & $5^{\circ}$ \\
\hline G3 & 1,14 & $4^{\circ}$ \\
\hline G8 & 0,69 & $6^{\circ}$ \\
\hline G7 & $-0,18$ & $7^{\circ}$ \\
\hline G6 & $-0,91$ & $8^{\circ}$ \\
\hline
\end{tabular}

Enfim, a tarefa final foi comparar os rankings gerados pela pesquisa documental e pelo levantamento e esse resultado pode ser observado na Tabela 8. A este ponto é importante enfatizar que houve duas coletas de dados por métodos distintos nos mesmos grupos, ou seja, foram criados oito grupos de investigação e foram realizadas duas coletas de dados em cada um deles, sendo uma por análise dos documentos produzidos no facebook $^{\circledR}$, como publicações e registros de 'curtir' e 'compartilhar' e outra pela aplicação de questionário.

Tabela 8 - Validação preditiva multimétodo

\begin{tabular}{|c|c|c|c|}
\hline Grupo & $\begin{array}{c}\text { Posição } \\
\text { Monitoramento }\end{array}$ & $\begin{array}{c}\text { Posição } \\
\text { Levantamento }\end{array}$ & $\begin{array}{l}\text { Alinhamento } \\
\text { entre os rankings }\end{array}$ \\
\hline G1 & $4^{\circ}$ & $5^{\circ}$ & Não \\
\hline G2 & $3^{\circ}$ & $3^{\circ}$ & $\mathrm{Sim}$ \\
\hline G3 & $5^{\circ}$ & $4^{\circ}$ & Não \\
\hline G4 & $1^{\circ}$ & $1^{\circ}$ & Sim \\
\hline G5 & $2^{\circ}$ & $2^{\circ}$ & Sim \\
\hline G6 & $8^{\circ}$ & $8^{\circ}$ & Sim \\
\hline G7 & $7^{\circ}$ & $7^{\circ}$ & Sim \\
\hline G8 & $6^{\circ}$ & $6^{\circ}$ & Sim \\
\hline
\end{tabular}

Fonte: elaborados pelos autores. 
Pelo princípio teórico da validação preditiva, ambas as coletas de dados devem convergir para um resultado único, demonstrando que há consistência na mensuração.

Observou-se que dos oito grupos testados, houve certa coincidência de resultados entre os dois rankings. Em verdade, apenas dois grupos não se comportaram como esperado, o que não compromete a validade do protocolo; a inversão de posição entre os grupos G1 e G3 pode ser devido ao tamanho da amostra, pois, o G3 teve a menor amostra no levantamento e o menor número de propagandas observadas no monitoramento. Credita-se então essa imprecisão à redução da qualidade do dado primário devido ao tamanho da amostra do grupo G3. Enfim, de posse das análises, é possível finalmente apresentar as conclusões do estudo no próximo tópico.

\section{ANÁLISE DOS DADOS}

Esta seção tem como objetivo apresentar os resultados dos testes com o público alvo em relação a sua atitude à propaganda no facebook $^{\circledR}$. Inicialmente é necessário justificar a delimitação do universo, pois embora se deva considerar o caráter de conveniência da amostragem com alunos de graduação e recém-formados, a parcela de jovens entre os usuários do facebook ${ }^{\circledR}$ existe e possui forte influência sobre diversos mercados que também possuem interesse em anunciar nesta mídia social - como a indústria de bebidas, cinema, vestuário e acessórios, produtoras de eventos, agências de viagens, concessionárias, instituições de ensino e outras. Para este estudo foi estipulada arbitrariamente a faixa etária de 18 a 35 anos como universo a ser pesquisado.

\subsection{ANÁLISES DESCRITIVAS DOS DADOS}

Foi realizada uma amostragem do tipo bola de neve que se iniciou com oito pessoas que foram consecutivamente convidando amigos na plataforma do facebook $^{\circledR}$ para responderem a pesquisa e este esforço resultou em 845 questionários válidos. O perfil médio

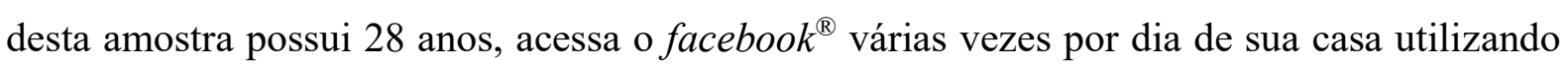
preferencialmente dispositivos móveis como smart phones.

Devido ao caráter da escala adotado, cada respondente deveria assinalar concordo, discordo ou indiferente para cada item da escala que foram tabulados respectivamente com os valores $1,-1$ e 0 , o peso da variável atitude para cada caso é representado pela soma 
aritmética dos pesos atribuídos pelo respondente aos itens obedecendo a proposta original de Lucian e Dornelas (2015) para análise de escalas de atitude binárias.

A média geral para o construto atitude foi de 2,06, representando que os respondentes possuem atitude positiva em relação à propaganda no facebook $^{\circledR}$. Algumas análises setorizadas também foram realizadas em busca de particularidades e são representadas nos Gráficos 1 e 2.

\section{Gráfico 1 - Escores de stitude por sexo}

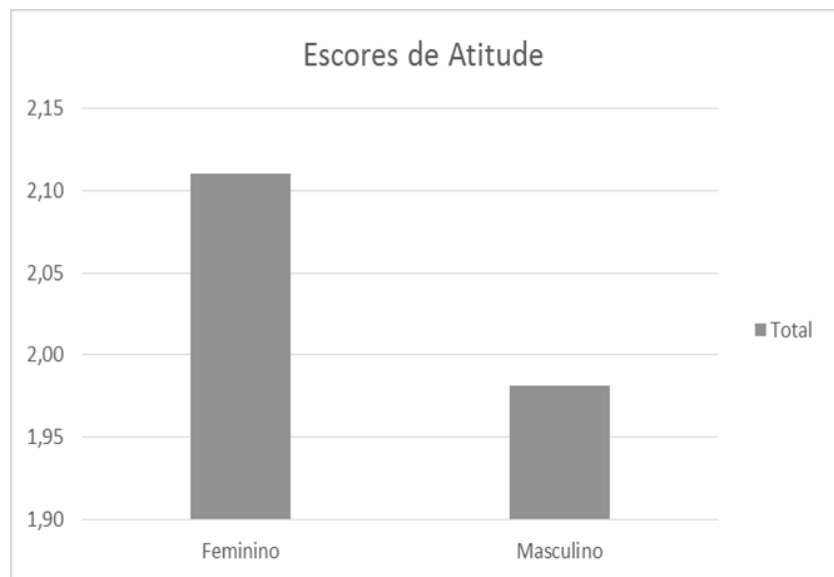

Fonte: elaborados pelos autores.

Na segmentação por sexo, foi verificado que as mulheres parecem ter atitude mais positiva que homens em relação à propaganda no facebook ${ }^{\circledR}$. Já na segmentação por frequência de acesso foi observado que as pessoas que acessam a plataforma de mídias sociais várias vezes ao dia possuem atitude mais positiva em relação à propaganda que os demais grupos.

\section{Gráfico 2 - Escores de atitude por frequência de acesso}

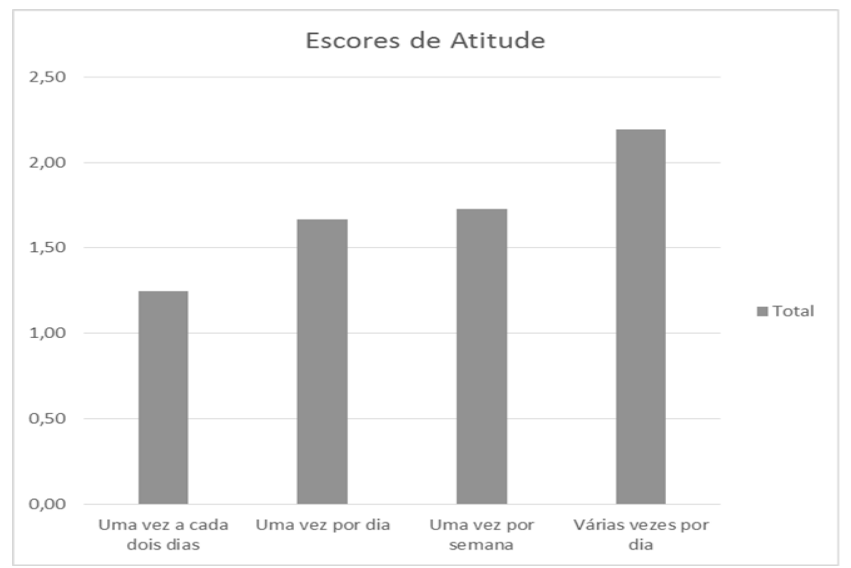

Fonte: elaborados pelos autores.

REAd | Porto Alegre - Vol. 23 - No 3 - Setembro / Dezembro 2017 - p. 189-217 
Se a análise for realizada individualmente por item da escala em busca das atitudes individuais para cada um dos atributos investiados é observado que todos os aspectos investigados de comunicação publicitária possuem em geral atitude positiva perante os usuários da rede social.

O Gráfico 3 de escores por itens da escala sustenta tal constatação e através dele é possível observar os extremos que são em opostos a interação dos usuários com as fanpages das empresas e com menor escore a intenção de compra pela plataforma do facebook ${ }^{\circledR}$.

As análises apontam, portanto, para um cenário onde as empresas são entidades aceitas na rede social facebook $^{\circledR}$, e sua interação através de comunicações publicitárias são objeto de atitude positiva.

\section{Gráfico 3 - Escore por itens da escala}

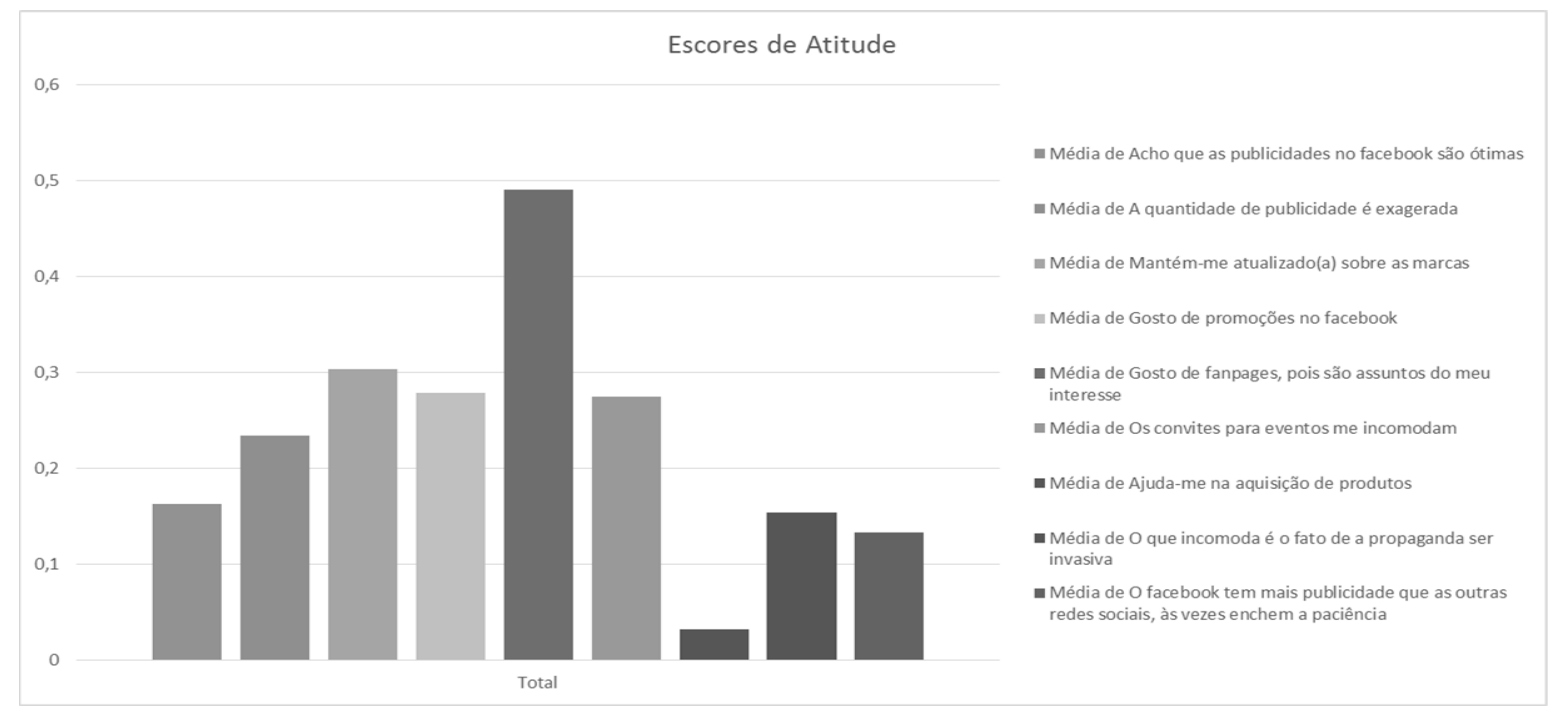

Fonte: elaborados pelos autores.

Os desdobramentos deste achado são apresentados na seção de conclusão.

\subsection{INTERPRETAÇÃO DOS DADOS}

Contrariando a corrente teórica que sugere a crise entre a comunicação das marcas com os indivíduos em ambientes de interação online como o facebook ${ }^{\circledR}$ (RAUSCHNABEL; KAMMERLANDERIVENS, 2016), a presente pesquisa identificou que a atitude positiva supera a negativa em relação à propaganda.

O debate focado no impacto negativo da exposição das marcas, normalmente investiga uma categoria psicológica de audiência conhecida como odiadores (SITORUS; 
IRWANSYAH, 2017). A partir da presente investigação empírica, os autores desta pesquisa entendem que tal traço psicológico de atacar as marcas não é um traço majoritário na população. Em outras palavras, existem mais consumidores pré-dispostos a curtirem e falarem bem das marcas do que consumidores propensos a atacá-las.

As diretrizes protetivas de Blizzard (2014) são um guia prático para as marcas se anteciparem aos efeitos negativos da rede, porém empiricamente foi demonstrado que há pouco o que se preocupar em relação a tal exposição. Ataques massivos só ocorrem por razões externas a propaganda, como falha de performance ou comportamento antiético.

Em relação ao achado de diferença sigficativa entre a atitude positiva das mulheres em relação aos homens, reitera-se que nada foi encontrado na literatura que explica-se tal comportamento. Os dados indicaram um padrão não procurado pelos autores desta pesquisa e seu real significado não pode ser conhecido com o atual arcabouço possuído. A interferência do acasou ou de viés de pesquisa não devem ser descartadas, entretanto, trata-se de um ponto sugestivo para futuros interessados no tema.

\section{CONCLUSÃO}

Este artigo teve como objetivo primário investigar qual a atitude de jovens consumidores em relação à propaganda no facebook ${ }^{\circledR}$ e para tal fim foi desenvolvida e validada uma escala de mensuração de atitude em relação à propaganda no facebook $^{\circledR}$. Assim como o objetivo central do estudo, o desenvolvimento da escala também representa uma contribuição para a academia e pode ser utilizada para estudos futuros.

Durante o processo de elaboração da escala os resultados dos testes realizados conferiram sucesso à validação e sugeriram que a escala elaborada com base no protocolo de Lucian e Dornelas (2015) é coerente e está apta para o uso.

Existem pelo menos duas formas de aplicar a escala recém-criada, para uso geral ou específico por alguma marca. Em seu formato original ela é capaz de mensurar a atitude do público em relação à propaganda no facebook $^{\circledR}$ de forma ampla, os respondentes irão se posicionar sobre o escopo da mídia social e sua aceitação, neste fim a escala é de grande valia para os estudos acadêmicos que pretenderem mensurar atitude de determinados perfis de público específicos.

Seu uso alternativo é a aplicação comercial, onde as empresas irão mensurar a atitude do público alvo em relação exclusivamente a sua marca. Para este fim é necessário 
especificar aos respondentes que as perguntas são todas relativas à determinada marca. A escala elaborada por esta pesquisa então é apresentada no Quadro 6.

\section{Quadro 6 - Escala elaborada}

\begin{tabular}{|l|l|l|l|}
\hline \multicolumn{1}{|c|}{ Afirmações } & Concordo & Discordo & Indiferente \\
\hline Acho que as propagandas no facebook® são ótimas. & & & \\
\hline A quantidade de propaganda é exagerada. & & & \\
\hline Mantém-me atualizado (a) sobre as marcas. & & & \\
\hline Gosto de promoções no facebook®. & & & \\
\hline Gosto das fanpages, pois são assuntos do meu interesse. & & & \\
\hline Os convites para eventos me incomodam. & & & \\
\hline Ajuda-me na aquisição de produtos. & & & \\
\hline $\begin{array}{l}\text { O facebook® tem mais propaganda que as outras redes } \\
\text { sociais, às vezes enchem a paciência. }\end{array}$ & & & \\
\hline O que incomoda é o fato de a propaganda ser invasiva. & & & \\
\hline
\end{tabular}

Fonte: elaborados pelos autores.

Em seguida a elaboração e validação da escala, o instrumento recém-criado foi utilizado para mensurar a atitude de consumidores jovens em relação a sua atitude a propaganda no facebook $k^{\circledR}$. Concluiu-se que esse público possui atitude positiva em relação às comunicações publicitárias, fato que deve estimular as empresas a investirem nesta mídia social como canal de comunicação publicitária.

Os dados fornecem também subsídio para elaboração de estratégias de marketing das empresas, a primeira delas é tida ao revelar a suscetibilidade das mulheres à propaganda online nesta mídia social em questão. As empresas de posse desta informação podem planejar campanhas para jovens entre 18 e 35 anos utilizando o facebook ${ }^{\circledR}$ como mídia principal.

Outra constatação importante para os delineamentos estratégicos é o registro de que os usuários possuem atitude positiva em relação as fanpages, ou seja, esta ferramenta deve ser explorada no facebook ${ }^{\circledR}$ prioritariamente as outras opções de comunicação publicitária, de acordo com o levantamento aqui realizado.

Ao se constatar que a dimensão com menor atitude positiva é referente a aquisição de produtos no facebook ${ }^{\circledR}$ observa-se uma clara oportunidade de pesquisa, pois mesmo sabendo que a mídia social não possui plataforma de pagamento e, portanto, é incompleta para realização de transações online, esta distância psicológica entre a propaganda e a intenção de compra deve ser reduzir, e estudos futuros podem investigar de que forma as empresas podem aproximar mais os consumidores jovens da aquisição de produtos no facebook $^{\circledR}$.

Para esta estratégia de redução da distância entre a fanpage e a compra, deve-se levar em consideração tanto a opção atual existente de link de migração para sites de e-commerce

REAd | Porto Alegre - Vol. 23 - No 3 - Setembro / Dezembro 2017 - p. 189-217 
como elaboração e proposição de novos modelos de negócio que permitam posicionar o momento da compra mais próximo aos usuários do facebook.

\section{REFERÊNCIAS}

AGGARWAL, P.; VAIDYANATHAN, R.; CASTLEBERRY, S. Managerial and Public Attitudes Toward Ethics in Marketing Research. Journal of Business Ethics, v. 109, n. 4, p. 463-481, 2011.

ANDREASSEN, C. et al. Development of a Facebook Addiction Scale. Psychological Reports, v. 110, n. 2, p. 501-517, 2012.

BLIZZARD, S. Don't feed the hackers: how your attitude to data security could affect business. Network Security, v. 2014, n. 5, p. 18-20, 2014.

CHEN, K.; KIM, J.; LIN, J. The effects of affective and cognitive elaborations from Facebook posts on consumer attitude formation. Journal of Consumer Behaviour, v. 14, n. 3, p. 208-218, 2015.

DE VRIES, L.; GENSLER, S.; LEEFLANG, P. Effects of Traditional Advertising and Social Messages on Brand-Building Metrics and Customer Acquisition. Journal of Marketing, v. 81, n. 5, p. 1-15, 2017.

DEBATIN, B. et al.. Facebook and Online Privacy: Attitudes, Behaviors, and Unintended Consequences. Journal of Computer-Mediated Communication, v. 15, n. 1, p. 83-108, 2009.

EGEBARK, J.; EKSTRÖM, M. Like What You Like or Like What Others Like? Conformity and Peer Effects on Facebook. SSRN Electronic Journal, 2011.

ELLISON, N.; STEINFIELD, C.; LAMPE, C. The Benefits of Facebook "Friends:" Social Capital and College Students' Use of Online Social Network Sites. Journal of ComputerMediated Communication, v. 12, n. 4, p. 1143-1168, 2007.

ERMIŞ, S. Desing in new media practices: A review on facebook ads as a social network.

Global Journal of Arts Education, v. 6, n. 1, p. 20, 2016.

ETIKAN, I. Combination of Probability Random Sampling Method with Non Probability Random Sampling Method (Sampling Versus Sampling Methods). Biometrics \& Biostatistics International Journal, v. 5, n. 6, 2017.

EXAME. Brasil é o $4^{\mathbf{0}}$ país em número de usuários de internet. Disponível em: $<$ https://exame.abril.com.br/tecnologia/brasil-e-o-4o-pais-em-numero-de-usuarios-deinternet/>. Acesso em: 7 maio. 2018.

REAd | Porto Alegre - Vol. 23 - No 3 - Setembro / Dezembro 2017 - p. 189-217 
HALIM, N.; MAROS, M. The Functions of Code-switching in Facebook Interactions.

Procedia - Social and Behavioral Sciences, v. 118, p. 126-133, 2014.

JACOBY, J.; MATELL, M. Three-Point Likert Scales Are Good Enough. Journal of Marketing Research, v. 8, n. 4, p. 495, 1971.

KO, Y. et al.. Determinants of consumer attitude toward corporate sponsors: A comparison between a profit and nonprofit sport event sponsorship. Journal of Consumer Behaviour, v. 16, n. 2, p. 176-186, 2016.

KOC, M. A study on Mersin in organizational culture reflections culture electronic network.

Pressacademia, v. 2, n. 1, p. 254-254, 2016.

KOMORITA, S. Attitude Content, Intensity, and the Neutral Point on a Likert Scale. The Journal of Social Psychology, v. 61, n. 2, p. 327-334, 1963.

KUCHARSKA, W. Consumer Social Network Brand Identification and Personal Branding. How Do Social Network Users Choose Among Brand Sites? SSRN Electronic Journal, 2017.

LEDBETTER, A. et al.. Attitudes Toward Online Social Connection and Self-Disclosure as Predictors of Facebook Communication and Relational Closeness. Communication Research, v. 38, n. 1, p. 27-53, 2010.

LIKERT, R. A technique for the measurement of attitudes. Archives of Psychology. n. 140, p. 44-53, 1932.

LINDEGAARD, L. Doing focus group research: Studying rational ordering in focus group interaction. Discourse Studies, v. 16, n. 5, p. 629-644, 2014.

LUCIAN, R.; DORNELAS, J. Mensuração de Atitude: Proposição de um Protocolo de Elaboração de Escalas. Revista de Administração Contemporânea, v. 19, n. $2^{a}$ Edição Especial, p. 157-177, 2015.

MARTIN, B. et al.. How to stop binge drinking and speeding motorists: Effects of relationalinterdependent self-construal and self-referencing on attitudes toward social marketing. Journal of Consumer Behaviour, v. 12, n. 1, p. 81-90, 2013. MORGAN, D. Focus groups as qualitative research. Thousand Oaks, Calif. [u.a.]: Sage Publ, 2009.

MOSES, T.; KIM, Y. Stabilizing Conditional Standard Errors of Measurement in Scale Score Transformations. Journal of Educational Measurement, v. 54, n. 2, p. 184-199, 2017. NAM, C.; DONG, H.; LEE, Y. Factors influencing consumers' purchase intention of green sportswear. Fashion and Textiles, v. 4, n. 1, 2017. 
NELSON, R. A chronology and glossary of propaganda in the United States. Westport, Conneticut: Greenwood Press, 1996.

ORR, E. et al.. The Influence of Shyness on the Use of Facebook in an Undergraduate Sample. CyberPsychology \& Behavior, v. 12, n. 3, p. 337-340, 2009.

PASQUALI, L. A medida psicométrica. 2. ed. Petrópolis: Editora Vozes, 2003.

RAUSCHNABEL, P.; KAMMERLANDER, N.; IVENS, B. Collaborative Brand Attacks in Social Media: Exploring the Antecedents, Characteristics, and Consequences of a New Form of Brand Crises. Journal of Marketing Theory and Practice, v. 24, n. 4, p. 381-410, 2016. SABRA, J. "I Hate When They Do That!" Netiquette in Mourning and Memorialization Among Danish Facebook Users. Journal of Broadcasting \& Electronic Media, v. 61, n. 1, p. 24-40, 2017.

SOCIALBAKERS. August 2017 Social Marketing Report Brazil. Disponível em: $<$ https://www.socialbakers.com/resources/reports/brazil/2017/august/>. Acesso em: 7 maio. 2018.

SHU, L.; SCHWARZ, R. IRT-Estimated Reliability for Tests Containing Mixed Item Formats. Journal of Educational Measurement, v. 51, n. 2, p. 163-177, 2014.

SITORUS, A.; IRWANSYAH, I. Fenomena Haters Sebagai Dampak Negatif Perkembangan Media Sosial Di Indonesia [The Phenomena of Haters and the Negative Impact of Social Media Development in Indonesia]. Polyglot: Jurnal Ilmiah, v. 13, n. 2, p. 23, 2017. SMITH, B.; LASSWELL, H. Propaganda, Communication and Public Opinion. Princeton: Princeton University Press, 2015.

TAUSCH, A.; MENOLD, N. Methodological Aspects of Focus Groups in Health Research. Global Qualitative Nursing Research, v. 3, p. $233339361663046,2016$.

TIKNO, T. Exploring the Acceptance for Pixel Technology Implementation in Facebook Ads among Advertisers in Indonesia. KnE Social Sciences, v. 3, n. 1, p. 96, 2018.

WU, S.; LIN, C.; LIN, J. An empirical investigation of online users' keyword ads search behaviours. Online Information Review, v. 35, n. 2, p. 177-193, 2011.

YUNG, C. From Digital Divide to Facebook Divide, Reconstruct our Target Market Segments with Facebook Native and Facebook Immigrant. Jaipuria International Journal of Management Research, v. 3, n. 1, p. 8, 2017.

ZHANG, X. et al. Characteristic tracking position and attitude measurement method based on PMD camera. Journal of Electronic Measurement and Instrument, v. 27, n. 7, p. 640-646, 2014.

REAd | Porto Alegre - Vol. 23 - No 3 - Setembro / Dezembro 2017 - p. 189-217 